\title{
CROSS-CULTURAL ANALYSIS OF CONFERENCE ABSTRACTS
}

\author{
Renata Povolná
}

\begin{abstract}
Writing an abstract in English, including an abstract for a conference presentation, has become an essential skill for all scholars who intend to present their research to an international academic audience. Now that English has become the dominant language of all academic and research communication, scholars from different language and cultural backgrounds have to master the writing of this research-progress genre (Swales 1990) since otherwise they may risk being refused participation at conferences and publication of their research findings in conference proceedings. The paper analyses the rhetorical structure of 80 conference abstracts with the aim of ascertaining whether there is any cross-cultural variation between abstracts written by Anglophone writers and non-native speakers of English. The latter are represented by researchers from the Czech Republic and some other countries where Slavonic languages are spoken, namely Slovakia, Poland and Ukraine. In addition, the rhetorical organization of the conference abstracts analysed is compared to that usually associated with research article (RA) abstracts. The findings of this corpus-based genre analysis reveal cross-cultural differences in the rhetorical organization of conference abstracts (CAs) and provide evidence that CAs and RA abstracts differ with regard to both number and types of moves. The study also provides recommendations for future conference calls and novice writers who intend to publish in English as an additional language.
\end{abstract}

\section{Keywords}

conference abstracts, cross-cultural variation, native and non-native speakers of English, rhetorical structure, rhetorical moves, patterns of move sequences, textual organization

\section{Introduction}

Since English has become the unequivocal lingua franca of academia, scholars from all fields of study have to write and publish their research findings in English, in particular if they want to be appreciated by their discourse communities and internationally recognized in their research fields. "No finding, discovery, or insight has any validity until it has gained peer approval through publication in a journal" (Tse \& Hyland 2010: 1880) and thus "publication can be seen as documentary evidence that the writer qualifies for membership in the target discourse community" (Swales 1900: 7). The use of English as an additional language has also become an important prerequisite for scholars who intend to present their research to an academic audience at international conferences, where 
English is usually the only conference language. Consequently, the writing of academic texts in one's native language, such as Czech or Slovak, has become of minor importance, and even if someone writes and publishes in their local native language, then at least an abstract in English is required. This includes not only abstracts to RAs, but also CAs sent to conference organizers prior to receiving an invitation to a conference. Conference organizers usually perform the role of reviewers and gate-keepers with the right to accept or refuse an abstract for a presentation at a conference and subsequent publication of research findings in conference proceedings, journals or thematic volumes.

In the process of the growing internationalization of all scholarship and with the ever-increasing amount of information that needs to be published and disseminated all over the world, English indisputably performs the role of a global lingua franca of academia and therefore publishing in international journals is now almost synonymous with publication in English (Lillis \& Curry 2010: 6). However, not all scholars writing in English use the same variety and, as evidenced by many studies on academic discourse (e.g. Chamonikolasová 2005, Stašková 2005, Mur-Dueňas 2008, Bennett 2010, Pérez-Llantada 2011, Schmied 2011, Wagner 2011, Povolná 2012, Dontcheva-Navratilova 2012), there is cross-cultural variation which may concern both form and content of academic texts written in English. This variation is caused by writing habits and language- and culture-specific conventions which experts conducting research in different fields of study transfer from their local native language to the texts they have to produce in English as an additional language (Hedgcock 2005). Since the overwhelming majority of writers and readers of scholarly texts written in English are not native speakers, the question arises whether it is appropriate and justifiable to impose the academic writing style conventions typical of the dominant Anglophone discourse community on international academic communication and whether qualities such as clarity, economy, structured rational argument supported by evidence, facts clearly distinguished from opinions, and precision in communication (cf. Bennett 2015) should be viewed from the perspective of native speakers of English, i.e. "the native speaking minority" (Mauranen et al. 2010), or from the perspective of authors from communities who speak languages other than English, such as Czech or Slovak.

The writing of a self-contained abstract can be a difficult and demanding task for non-native speakers of English who, while being "under a great deal of pressure to publish in English" (Bennett 2013: 41) are forced to write their abstracts in English in order to get their articles published in international journals and/or have their presentations accepted at international conferences. The construction of this essential form of writing (Swales \& Feak 2009), which 
is expected to summarize scholarly work in clear and compelling ways, has to meet certain requirements (e.g. relevant topic, number of words, keywords) and comprise statements about motivation, problems, approaches, results and conclusions. The goal of an abstract is to entice readers and 'sell' one's research findings, i.e. to persuade reviewers to accept one's paper and motivate conference participants to attend one's presentation. Thus scholars who are nonnative speakers of English are faced with the challenge of acquiring academic writing skills in English and have to adopt an academic writing style that is to a large extent shaped by Anglophone writing conventions, irrespective of their local native language writing conventions.

\section{Aim and research questions}

The research goal of this study is to find out whether there is any cross-cultural variation between conference abstracts written by Anglophone writers and nonnative speakers of English, i.e. to discover differences and similarities between abstracts written by native speakers of English and non-native expert writers, namely Czech, Slovak, Polish and Ukrainian speakers of English. In addition, the rhetorical structure of the conference abstracts analysed is compared to that usually associated with RA abstracts (Hyland 2000, Swales \& Feak 2009), in particular with regard to number and types of moves and patterns of sequences of particular types of moves applied in abstracts. In addition, the author hopes to draw some recommendations for future conference calls and novice writers who intend to publish in English as an additional language.

In order to meet the goals of the investigation, the following research questions have been formulated:

RQ 1: Is there any cross-cultural variation in the writing of conference abstracts?

RQ 2: Is the rhetorical structure of CAs in correspondence with the rhetorical organization and types of moves traditionally ascribed to RA abstracts?

RQ 3: Is the textual organization of CAs written by non-native speakers of English different from that of native speakers?

RQ 4: Does the rhetorical structure of CAs comprise five moves?

\section{Corpus and methodology}

\subsection{Corpus}

The study is based on a specialized corpus (cf. Flowerdew 2004) comprising 80 conference abstracts accepted between 2008 and 2014 for presentation at the international Brno Conference on Linguistics Studies in English, which is 
held every other year at the Faculty of Education, Masaryk University, Brno, Czech Republic. All the CAs analysed are single-authored abstracts which address the same audience and are associated with empirical research in the area of linguistics studies. Since previous studies on rhetorical organization have indicated that variation in disciplines can influence rhetorical structure and language means used in academic texts (e.g. Swales 1990), only abstracts based on empirical research have been selected in order to avoid consideration of differences between presentations concerned with empirical and theoretical research (cf. Pho 2008).

It must also be noted that abstracts written by novice authors, such as Ph.D. students presenting at an international conference for the first fime, have been excluded from the corpus since it is believed that it would be unfair to compare novice writers of Slavonic origin with expert Anglophone writers, for example. Since the greatest number of abstracts were written by Czech authors, it has been possible to analyse ten abstracts by Czech speakers of English from every conference selected for the analysis, namely ten abstracts from 2008, ten from 2010, ten from 2012 and ten from 2014, so that tendencies and differences between the writing of abstracts by Czech authors in the period between 2008 and 2014 are revealed. As regards the numbers of abstracts by Anglophone and some other Slavonic writers, it has been possible to include ten abstracts from each group in the investigation. Therefore, ten abstracts by native speakers of English, ten by Slovak, ten by Polish and ten by Ukrainian authors have been analysed, amounting altogether to 80 conference abstracts.

\subsection{Methodology}

The present research is a corpus-based contrastive study of the discourse organization of texts from one genre which applies the methods of the rhetorical structure theory, namely the tools of move analysis as represented by Swales (1981, 1990), Samraj (2005), Bhatia (1993), Connor and Upton (2004). The structure of the conference abstracts has been analysed in terms of the rhetorical moves traditionally ascribed to abstracts as suggested by Hyland (2000) and Swales and Feak (2009), i.e. introduction, purpose, methods, results and conclusion. Individual moves and types of moves have been identified solely according to the function and content of the text, i.e. using the top-down approach introduced by Biber et al. (2007) in order to avoid circularity of the identification of rhetorical moves and linguistic realizations which can occur while using both top-down (from function to form) and bottom-up (from form to function) approaches.

The individual types of moves have been identified in agreement with the five-move pattern proposed by Santos (1996) for RA abstracts, namely Move 
1 - Situating the research (STR), Move 2 - Presenting the research (PTR), Move 3 - Describing the methodology (DTM), Move 4 - Summarizing the findings (STF) and Move 5 - Discussing the research (DTR). Santos's model has been applied here because it has been used for the analysis of abstracts from the area of applied linguistics, which are similar to the data under investigation here, because it comprises all the moves identified in previous studies (cf. above) and because it uses labels that seem "more meaningful than those applied in other studies" (Pho 2008: 234), such as introduction, purpose, methods, results and conclusion. Unlike Santos's study, this investigation does not divide the five types of moves into further submoves, as these are mostly problematic to recognize unambiguously. This simplification is in agreement with Swales (2004), who admitted that the submoves in his CARS model were sometimes difficult to distinguish.

Since the length of particular types of moves may be relatively short, as abstracts tend to be condensed texts, the move as a basic unit in the present analysis can be realized by structures ranging from a word or a phrase up to several sentences representing whole paragraphs. A move has a particular minor communicative function and in turn the whole sequence of moves within an abstract serves the major communicative purpose of the whole genre, i.e. the genre of conference abstracts (cf. Santos 1996: 458).

After identifying and describing the individual moves and their types a comparative analysis of the number and types of moves and patterns of sequences of moves between writers from different backgrounds was conducted with regard to the research questions formulated in Section 2 above, with special attention paid to comparison with the types and patterns traditionally associated with RA abstracts.

\section{Findings and discussion}

Since the study is concerned solely with the rhetorical organization of the conference abstracts analysed (i.e. the macrolevel of textual organization and content of CAs), the following section is divided into two parts, i.e. Section 4.1, which presents findings concerning the total number of moves and their particular types, and Section 4.2, which concentrates on the patterns of sequences of individual types of moves typical of CAs.

\subsection{Moves and types of moves}

The number of moves traditionally ascribed to the rhetorical organization of RA abstracts is five (cf. above). As the results given in Table 1 show, the structure of CAs is slightly different. The overwhelming majority of abstracts analysed 
comprise two to four moves (73 altogether). Only three abstracts consist of five moves. The highest number of abstracts (i.e. 26) comprise two moves only, which is most noticeable in the case of Ukrainian writers (cf. Example 1) and Czech writers from 2008 (5 of 10 in each group). Next in order of frequency come abstracts comprising three moves (25). The rhetorical structure with three moves is typical of native speakers of English ( 5 of 10 writers) and two groups of Czech writers, namely those from 2010 and 2012 (4 in both groups). Conference abstracts with four moves are mostly represented by two or three writers in each group (22 altogether). This case is illustrated in Example 2, which is taken from the CAs by native speakers of English.

Example 1:

FOCUSING AS THE DISCOURSE STRATEGY OF INFORMATION REPRESENTATION

Meaningful language units while functioning in discourse reveal communicative aims of the speaker/writer. Thus they are basically used for representing the intentional side of discourse. If the speaker/writer wants to add a strong emotional impact to either a whole utterance or to one of its parts, the strategy of focusing may be applied.

Focusing as a strategy of foregrounding specific information by means of giving it emotional colouring helps the speaker/writer to shape the pragmatic core of discourse. Very often words and phrases used occasionally are attributed for gaining this task (That's out and out communism [M. Quin]; He had to listen while Andre's wife told him she was piss-poor /.../ [E. Leonard]]. They appear due to the cognitive operation of human creative activity for satisfying the demands of transmitting information. $<\mathrm{STR}>$

The article attempts to prove that any transformation of semantic, syntactic or discourse function possesses significant potential for representing the speaker's/writer's strategy of focusing the information in discourse. $<\mathrm{PTR}>$

(Ukr.)

Example 2:

AMERICAN REGIONAL LEXICAL SURVEY: GENDER AND AGE IN LEXICAL CHANGE IN THE SOUTHERN UNITED STATES

The South is a very distinctive region in the United States. Linguistically, its history has had several impacts. Firstly, Southern speech is stigmatized. Secondly, Southerners, aware of this stigma, are linguistically insecure. Finally, increasing urbanization of the South brings people from many different dialect regions together. All these factors can motivate changes in Southern speech. $<\mathrm{STR}>$

Using data from a survey, participants originating from the American South were given index scores that determined how Southern he or she was, i.e. how many regional Southern lexical items s/he uses. These results were then categorized according to gender and age. $<$ DTM $>$

This paper explores the ongoing changes in lexical choice in the Southern United States by comparing generations and gender. $<\mathrm{PTR}>$ In terms of the bigger picture of English in the world, the results from this survey show the effects of changing population demographics and labor statistics on choice of regional lexical items. $<\mathrm{STF}>$

(NSs) 


\begin{tabular}{|c|c|c|c|c|c|c|c|c|c|}
\hline No. of moves & NSs & $\begin{array}{l}\text { Czech } \\
2008\end{array}$ & $\begin{array}{l}\text { Czech } \\
2010\end{array}$ & $\begin{array}{l}\text { Czech } \\
2012\end{array}$ & $\begin{array}{l}\text { Czech } \\
2014\end{array}$ & Slovak & Polish & Ukr. & $\begin{array}{l}\text { Total } \\
(80 \text { CAs })\end{array}$ \\
\hline 6 moves & 0 & 0 & 0 & 0 & 1 & 0 & 0 & 0 & 1 \\
\hline 5 moves & 0 & 1 & 0 & 0 & 1 & 0 & 1 & 0 & 3 \\
\hline 4 moves & $\mathbf{3}$ & $\mathbf{2}$ & $\mathbf{2}$ & $\mathbf{3}$ & $\mathbf{5}$ & $\mathbf{2}$ & $\mathbf{3}$ & $\mathbf{2}$ & $\mathbf{2 2}$ \\
\hline 3 moves & $\mathbf{5}$ & $\mathbf{2}$ & $\mathbf{4}$ & $\mathbf{4}$ & $\mathbf{2}$ & $\mathbf{3}$ & $\mathbf{3}$ & $\mathbf{2}$ & $\mathbf{2 5}$ \\
\hline 2 moves & $\mathbf{2}$ & $\mathbf{5}$ & $\mathbf{4}$ & $\mathbf{3}$ & $\mathbf{1}$ & $\mathbf{3}$ & $\mathbf{3}$ & $\mathbf{5}$ & $\mathbf{2 6}$ \\
\hline 1 move & 0 & 0 & 0 & 0 & 0 & 2 & 0 & 1 & 3 \\
\hline
\end{tabular}

Table 1: The total number of moves in all conference abstracts (including repeated moves)

Apart from the overall findings as stated above, between 2008 and 2014 there seems to be a tendency in the writing of CAs by Czech writers to apply a higher number of moves, since the prevailing two-move pattern used in 2008 changes progressively into a four-move pattern in 2014, where it is represented by five CAs. However, it must be stressed here that the results in Table 1 are based on the total number of moves without distinguishing particular types.

As explained in Section 3.2 above, there are five possible types of moves that can be distinguished in the rhetorical organization of abstracts. As with the total number of moves, the number of different types of moves in the corpus is different from that typically associated with RA abstracts. A closer look at the frequency rates in Table 2 reveals that the majority of all abstracts in the data (67) comprise only two or three different types. These are rather unexpected findings, which need further discussion and clarification.

\begin{tabular}{|l|c|c|c|c|c|c|c|c|l|}
\hline No. of types & NSs & $\begin{array}{l}\text { Czech } \\
2008\end{array}$ & $\begin{array}{l}\text { Czech } \\
2010\end{array}$ & $\begin{array}{l}\text { Czech } \\
2012\end{array}$ & $\begin{array}{l}\text { Czech } \\
2014\end{array}$ & Slovak & Polish & Ukr. & $\begin{array}{l}\text { Total } \\
(80 \text { CAs })\end{array}$ \\
\hline 5 types & 0 & 0 & 0 & 0 & 1 & 0 & 0 & 0 & 1 \\
\hline 4 types & 3 & 1 & 2 & 0 & 2 & 0 & 1 & 0 & 9 \\
\hline 3 types & $\mathbf{5}$ & $\mathbf{3}$ & $\mathbf{4}$ & $\mathbf{6}$ & $\mathbf{4}$ & $\mathbf{3}$ & $\mathbf{5}$ & $\mathbf{2}$ & $\mathbf{3 2}$ \\
\hline 2 types & $\mathbf{2}$ & $\mathbf{6}$ & $\mathbf{4}$ & $\mathbf{4}$ & $\mathbf{3}$ & $\mathbf{5}$ & $\mathbf{4}$ & $\mathbf{7}$ & $\mathbf{3 5}$ \\
\hline 1 type & 0 & 0 & 0 & 0 & 0 & 2 & 0 & 1 & 3 \\
\hline
\end{tabular}

Table 2: The number of different types of moves in all conference abstracts 
Table 2 provides evidence of certain cross-cultural variation in the movepatterns typical of particular groups of writers. While native speakers of English and Polish writers prefer a rhetorical pattern with three different types of moves when producing CAs in English (5 in each group), Ukrainian and Slovak writers give clear preference to a two-type pattern. The latter pattern, which is taken from the CAs by Slovak writers, follows:

Example 3:

TO-INFINITIVE CLAUSES IN ACADEMIC DISCOURSE - NATIVE AND NONNATIVE WRITERS COMPARED

The objective of the paper is to examine the use of non-finite clauses, more specifically to-infinitive clauses, in written academic discourse and the application of their syntactic and semantic properties in the selected corpus. Based on Quirk's et al. (1985) subdivision they can be viewed as formal means of text formation and may have nominal, relative and adverbial meaning. This functional classification resembles to some extent that of subclausal units such as noun phrases and adverbs. $<\mathrm{PTR}>$ The presented analysis focuses on subordinate to-infinitive clauses in the selected papers found in Topics in Linguistics, an international scientific journal published by the Department of English and American Studies, Faculty of Arts, Constantine the Philosopher University in Nitra. Moreover, it tries to investigate possible differences in the application of the presented structure by the native and non-native writers of English. $<$ DTM $>$

(Slovak)

As regards the move-pattern commonly used by Czech scholars, both the most frequent patterns, i.e. the two- and three-move patterns, are applied with the same total frequency rate. This entails a total of 17 CAs with a two-move pattern and the same number with a three-move pattern. However, as with the number of moves (irrespective of their types), between 2008 and 2014 there seems to be a tendency in the writing of abstracts by the Czechs to apply a higher number of different types of moves. It is also worth noting that in the 2014 group there are three abstracts which comprise more than three different types of moves while in the 2008 group there is only one abstract with four different types.

This variation between the groups included in the study may be because of different language-specific writing conventions, which in the case of most Slavonic writers, for example, allow for a number of digressions when a scholarly text in the local native language is composed (cf. e.g. Č́mejrková \& Daneš 1997, Chamonikolasová 2005, Povolná 2012). In turn this can be reflected in the much greater length of particular types of moves when writing in English, thus preventing the author from including all possible types in CAs because there are usually limits stated by conference organizers on the total length of abstracts and the number of words. In addition, there seems to be another, even more important reason: the fact that many scholars do not usually have their research findings available when producing an abstract for a conference they wish to attend, or 
they intend to present and discuss the theoretical framework and methodology of the intended research, so that they are not even able or ready to include Move 4 (Summarizing the findings; STF) and, consequently, Move 5 (Discussing the research; DTR) into their CAs.

\subsection{Patterns of move sequences}

Before discussing the results concerning the patterns of move sequences typically applied by the groups of writers under scrutiny, it is necessary to look at those from the analysis of the individual possible types of moves. As can be seen from Table 3, Move 2 (Presenting the research; PTR) is an integral component of all CAs. The inclusion of this type of move into the rhetorical structure of abstracts seems quite logical because its communicative function is to inform the audience about the purpose of the presentation and/or provide description of the key features of the research in question, i.e. it takes either a purposive or decriptive form, to use Santos's words (1996). There is only one exception - an abstract by one Ukrainian writer, which does not include Move 2 and thus is responsible for a lower average result than 100 per cent $(99 \%)$. As for the other possible types of move, there is considerable cross-cultural variation, which is discussed below.

\begin{tabular}{|l|c|c|c|c|c|c|c|c|c|}
\hline Move type & NSs & $\begin{array}{l}\text { Czech } \\
2008\end{array}$ & $\begin{array}{l}\text { Czech } \\
2010\end{array}$ & $\begin{array}{l}\text { Czech } \\
2012\end{array}$ & $\begin{array}{l}\text { Czech } \\
2014\end{array}$ & Slovak & Polish & Ukr. & Total \\
\hline STR & 80 & 80 & 90 & 90 & 60 & 40 & 80 & 70 & 74 \\
\hline PTR & $\mathbf{1 0 0}$ & $\mathbf{1 0 0}$ & $\mathbf{1 0 0}$ & $\mathbf{1 0 0}$ & $\mathbf{1 0 0}$ & $\mathbf{1 0 0}$ & $\mathbf{1 0 0}$ & $\mathbf{9 0}$ & $\mathbf{9 9}$ \\
\hline DTM & 90 & 50 & 70 & 50 & 80 & 60 & 70 & 50 & 65 \\
\hline STF & 40 & 20 & 20 & 20 & 40 & 10 & 20 & 0 & 21 \\
\hline DTR & 0 & 0 & 0 & 0 & 30 & 0 & 0 & 0 & 4 \\
\hline Aver. length & 181 & 162 & 166 & 181 & 210 & 162 & 168 & 218 & 181 \\
words & words & words & words & words & words & words & words & words \\
\hline
\end{tabular}

Table 3: Percentages of occurrence of particular types of moves in all conference abstracts

The CAs written by native speakers of English, which mostly comprise three different types of moves, include Move 1 (Situating the research; STR) and Move 3 (Describing the methodology; DTM) in 80 and 90 per cent respectively. Regarding Move 1, there is considerable variation among the groups of Slavonic 
writers, ranging from 40 to 90 per cent. While the majority of Czech writers (groups from 2008, 2010 and 2012) and Polish writers apply Move 1 with a frequency similar to Anglophone writers (80-90\%), the other groups include this type less frequently, namely 40 per cent in the case of Slovak and 70 per cent in the case of Ukrainian writers. The relatively frequent use of Move 1 (STR), amounting to an average of 74 per cent in the data, seems to be in agreement with Hyland's suggestion (2004) about this type of move finding its way into abstracts. The primary reason for the inclusion of Move 1 seems to be to attract the audience by locating the research to be presented in terms of research field, by stating that the topic is of crucial scientific concern, by referring to previous research and/or promising to extend previous research, as in the following example, which is taken from the CAs by Polish writers:

Example 4:

MONOLOGIC CONCESSIVE SCHEMATA IN DIALOGIC DISCOURSE - ON THE INTERACTIONAL NATURE OF JUDICIAL ARGUMENTATION

Viewed as a rhetorical figure in argumentation, concessio originally meant conceding the opponent's point in order to strengthen the arguer's position, while under the semanticsyntactic approach concession was regarded as a type of relation holding between clauses. Yet, the situational context of Concession, perceived as a discourse-pragmatic phenomenon, received little attention. $<\mathrm{STR}>$

Drawing on the interactional three-move concept of Concession designed by CouperKuhlen and Thompson (1999, 2000) and further advanced by Barth-Weingarten (2000, 2003), the author contributes a genre-based description of the realization of Concession in judicial discourse to show the interactional nature of legal decision-making. $<$ PTR $>$ The study has been carried out on a corpus of judgments issued by the European Court of Justice (now: Court of Justice). The analysis has revealed the most frequent monologic Concessive schemata and recurrent Concessive markers present in judicial argumentation. $<\mathrm{DTM}>$ As expected, the results suggest that writers, like speakers, are aware of, and follow the tripartite dialogic pattern of Concession found in spoken language. $<\mathrm{STF}>$

(Polish)

As for Move 3 (DTM), which is the third most common type in all CAs analysed (65\%), this type tends to be applied progressively between 2008 and 2014 by Czech writers (reaching $80 \%$ in the 2014 group) while among the other Slavonic groups its inclusion in the textual organization of CAs is slightly less common (50-70\%). This is a surprising finding since information about the materials, methods and variables of the research in question seem to be an obvious component of all abstracts. However, as indicated in Table 3, only two thirds of the writers in the data include this kind of information into their CAs (for embedded moves, cf. below). 
The results concerning Move 4 (Summarizing the findings; STF) are also slightly unexpected. In comparison with abstracts to RAs, the rhetorical structure of which usually comprises research findings, Move 4 appears only in 21 per cent of all CAs. Anglophone writers, whose abstracts are mostly quite compact, include this type in four cases $(40 \%)$. The same number applies this type of move only in the 2014 group of Czech writers. In all the other groups there are only one or two writers who include Move 4 (STF) in their CAs (10-20\%), as is the case of the Czech writer from the 2008 group in the example that follows:

Example 5:

BUILDING UP COHERENCE IN POLITICAL SPEECHES: THE STRATEGIC USE OF THE PRONOUN WE

The construction and negotiation of identities, social roles and interpersonal and institutional relations in the discourse of political speeches is the result of strategic choices which contribute to the perception of the existential coherence of the speaker and the discourse coherence of his/her speech. $<\mathrm{STR}>$ This contribution investigates the strategic use of the personal pronoun we for indicating choices related to the footing of the speaker and the legitimization and proximization strategies involved. $<\mathrm{PTR}>$ The analysis undertaken from a pragmatics and stylistics point of view is performed on a corpus of thirty speeches delivered by the last three Directors-General of UNESCO at the opening of international conferences and meetings. $<\mathrm{DTM}>$ The findings of the investigation suggest that the signals a speaker/writer may use to guide the listener/reader towards a coherent discourse interpretation are genre specific. $<\mathrm{STF}>$ Furthermore, the analysis scrutinizes idiosyncratic variation in the use of the pronoun we in the addresses of the three speakers. $<$ DTM $>$

(Czech 2008)

The above results are in agreement with my suggestion that scholars usually write CAs on research which is still in progress and therefore are not able to include a summary of their results (cf. research-process genres discussed in Swales 1990: 177). For example, Ukrainian writers, whose CAs in general comprise the lowest number of different types of moves, do not include Move 4 at all although their CAs rank among the longest ones in the data (218 words). Based on the results given in Table 3 above, it can now be tentatively stated that the length of a CA does not directly influence the number of different types of moves applied in its rhetorical structure. Only further analysis can prove whether my statement is justifiable or not, and this is, unfortunately, beyond the scope of the present paper.

As regards the inclusion of Move 5 (Discussing the research; DTR), results similar to those concerning Move 4 have been drawn. The discussion of research findings, which usually follows the summary of results in the textual organization of an abstract, have been found only exceptionally in the data, namely in three 
CAs by the 2014 group of Czech writers who have been able to apply this type of move (cf. Example 6). The average finding (4\%) is not at all in correspondence with Hyland's suggestion (2004) about Move 5 having an increasing tendency to become part of an abstract. However, it is important to stress here that Hyland's proposal is concerned with RA abstracts, which seem to have a slightly different rhetorical structure, in particular with regard to the inclusion of Move 4 and Move 5.

Example 6:

THE MARKED WORD ORDER AS A SYNTACTIC MEANS OF EMPHATIC EXPRESSIONS IN CHOSEN LITERARY SAMPLES

The word order as an important carrier of sentence dynamism has a substantial impact on the overall impression and effect a text will make on the addressee. With English and Czech, which represent typologically different languages, the Czech translation of the English sentences with marked word order, i.e. such structures, that serve the emphatic and expressive function of the language, represents a demanding and challenging phenomenon. $<\mathrm{STR}>$ The focus of this paper is on written language, more specifically on contemporary literary texts published in both the original and translated versions, and their analysis and comparison in terms of adequacy within the sentence dynamism. The subject to analysis is both the prototypical English marked syntactic structures, e.g. the inverted ones, as well as the marginal types, along with the frequency of adverbs and particles employed instead in the Czech versions of the same texts. The concurrent target of the observations is their application in the teaching process at tertiary level, covering namely seminars in translation, the syntax of the English language or linguistic analysis of text for university students of English. $<\mathrm{PTR}>$ Here the samples collected provide a useful resource for practising translation and increasing the students' awareness of the typological character of the English language. $<\mathrm{DTR}>$

(Czech 2014)

Differences between the typical rhetorical structure of RA abstracts, which as a rule comprises five different types of moves mostly applied in the order mentioned above (cf. Section 3.2 above), and the discourse organization of rhetorical moves of CAs analysed in this study are more noticeable in Table 4, which surveys typical patterns of move sequences applied in the corpus. At first sight it is obvious that Move 4 (STF) and Move 5 (DTR) are not even part of the most frequent move sequences. They occur only exceptionally in the table in the patterns listed as 'Other move sequences'. By comparison, the data prove that the rhetorical organization of CAs typically includes three different types of moves, listed here in order of frequency: Move 2 (Presenting the research; PTR), which is an integral part of all CAs analysed, Move 1 (Situating the research; STR), which is applied by three quarters of writers (74\%), and Move 3 (Describing the methodology; DTM), which is part of about two thirds of the CAs in the data (65\%) (cf. Table 3 above). Thus it can be stated that the authors usually submit their CAs at the time when they are not yet ready to include their research findings 
because their research is still in progress or because they intend to discuss only their theoretical framework and methodology, and therefore, quite logically, they cannot include any discussion of their research findings.

\begin{tabular}{|l|c|c|c|c|c|c|c|c|c|}
\hline Move sequence & NSs & $\begin{array}{l}\text { Cz. } \\
08\end{array}$ & $\begin{array}{l}\text { Cz. } \\
10\end{array}$ & $\begin{array}{l}\text { Cz. } \\
12\end{array}$ & $\begin{array}{l}\text { Cz. } \\
14\end{array}$ & Sl. & Pl. & Uk. & $\begin{array}{l}\text { Total } \\
(80 \text { CAs })\end{array}$ \\
\hline STR PTR DTM & 2 & 2 & $\mathbf{5}$ & $\mathbf{3}$ & 2 & 2 & $\mathbf{4}$ & 1 & $\mathbf{2 1}$ \\
\hline STR PTR & 1 & $\mathbf{4}$ & $\mathbf{3}$ & $\mathbf{3}$ & 1 & 0 & 2 & $\mathbf{4}$ & $\mathbf{1 8}$ \\
\hline PTR DTM & 1 & 0 & 0 & 0 & $\mathbf{3}$ & $\mathbf{3}$ & 1 & $\mathbf{3}$ & $\mathbf{1 1}$ \\
\hline STR DTM PTR & $\mathbf{4}$ & 0 & 1 & 1 & 0 & 0 & 0 & 0 & $\mathbf{6}$ \\
\hline PTR STR & 0 & 0 & 0 & 2 & $\mathbf{3}$ & 0 & 0 & 0 & $\mathbf{5}$ \\
\hline PTR STR (+another type) & 0 & 1 & 0 & 0 & 0 & 2 & 1 & 1 & $\mathbf{5}$ \\
\hline Other move sequences & 2 & 3 & 1 & 1 & 1 & 3 & 2 & 1 & $\mathbf{1 4}$ \\
\hline
\end{tabular}

Table 4: Most typical patterns of move sequences in all conference abstracts

As regards typical patterns of move sequences, STR PTR DTM, the most common pattern, has been applied by 21 writers, which entails more than one quarter of all CAs analysed. This pattern is illustrated by the following example taken from the 2010 group of Czech writers:

Example 7:

TRANSITIONAL VERBS OPERATING IN PRESENTATION SCALE SENTENCES WITHIN FICTION NARRATIVES

(An Attempt at a Dynamic and a Static Semantic Analysis)

Advocating a dynamic approach to the semantic analysis, the theory of functional sentence perspective (FSP) represents a logical counterpart of what is usually referred to as static semantics. In the framework of FSP, aptly elaborated by Jan Firbas (summarised in Firbas 1992), the English verb tends to be the mediator (i.e. transition) between the theme and the rheme. Every sentence implements one of the dynamic semantic scales, which functionally reflect the distribution of communicative dynamism and operate irrespective of word order. In principle, Firbas distinguishes two types of the dynamic semantic scales: the Presentation Scale and the Quality Scale. $<\mathrm{STR}>$

The present paper looks at the role of the English verb operating in Presentation Scale sentences within fiction narratives from the point of view of both dynamic and static semantics. $<$ PTR $>$ Especially the Firbasian phenomenon of presentation or appearance on the scene is examined and exemplified by means of statistical and FSP analysis of a sample corpus based on selected narrative texts by David Lodge and C. S. Lewis. $<$ DTM $>$

(Czech 2010) 
Together with STR PTR and PTR DTM patterns (the former shown in Example 1 and the latter in Example 3 above), the pattern STR PTR DTM represents 50 of $80 \mathrm{CAs}$ under investigation. Based on these results, it can now be stated that the majority of writers from all groups consider it important to start CAs with Move 1 (Situating the research) (47 altogether), as in Example 7, in which the author first places his research within the field of functional sentence perspective and only then explains exactly what his presentation is to be about. This position of Move 1 is in agreement with its placement in the rhetorical structure of RA abstracts. Second come writers who start CAs with Move 2 (Presenting the research) (30 in total). Only three of all 80 writers included in the study place Move 3 (Discussing the methodology) at the very beginning of their CAs (listed under 'Other move sequences' in Table 4).

Move 3, apart from coming second or third in the typical pattern of move sequences of CAs, is often embedded within the other types of moves, most typically within Move 2 . This is caused by the fact that Move 3 is often expressed by a short construction, such as a phrase or non-finite clause, which contributes to the compact nature of the abstract. Move 3 (DTM), expressed by a non-finite clause and embedded within Move 2 (PTR), is shown in the following example, which is taken from the 2012 group of Czech writers:

Example 8:

Therefore, the aim of this contribution is to show which face-threatening acts prevail in the sample corpus $<\mathrm{PTR}>$ comprising authentic Internet discussion boards dedicated to the afore-mentioned topics $<\mathrm{DTM}>$ and especially how the participants try to solve the potentially threatening situations via politeness. In addition, it also investigates whether there are mainly acts threatening positive or negative face, $<\mathrm{PTR}>$

(Czech 2012)

Cases of embedded moves similar to that in Example 8 have been found in 20 CAs in the corpus. Most of them are written by Czech and Slovak writers, who seem to be aware of the need to write a condensed abstract in order to receive an invitation to a conference and subsequent publication of research findings in conference proceedings.

Finally, it is necessary to mention here move cycles, which occur when at least two types of moves are repeated, thus resulting in the PTR STR or PTR DTM sequence being repeated twice. Move cycles have been identified in four cases in the data, all represented by Slavonic writers. One example follows:

Example 9:

SYNTACTIC FUNCTIONS OF NON-FINITE VERB FORMS IN A LEARNER CORPUS OF SPOKEN DISCOURSE

The aim of this paper is to present some findings resulting from the analysis of a small corpus of spoken English language. Apart from general comments on the structure of 
verbal phrases in the given corpus, attention is paid to the usage and frequency of nonfinite verb forms in their varied syntactic functions. $<\mathrm{PTR}>$ The results are compared with corpus findings included in Biber et al. (1999) and also considered according to contrastive interlanguage analysis (CIA), (Granger, 2009), which can help us assess a possible influence of the learners' native language (L1), Czech. The CIA analysis is only qualitative, based on the typological differences between the students' L1 and L2 (Mathesius, 1975, Knittlová et al., 2010). $<\mathrm{DTM}>$ The third aim is to suggest possible innovations in advanced language teaching/learning of the English language which may decrease L1 transfer, so that it becomes closer to the English native speakers' norms. $<$ PTR $>$

The analysed corpus (recorded in October and November 2013 and later transcribed) consists of a presentation of spoken English language of 112 first-year students of TEFL Programme from three Czech universities, whose knowledge should correspond to B2 level of CEFR. The corpus comprises about 74,000 words and includes three parts: a) a monologue where the students introduce themselves; b) reciprocal dialogues of all the students who need some information; c) discussion between the same pairs of students on given topics. $<$ DTM $>$

(Czech 2014)

The author in the above example starts her abstract by explaining her research aims (Move 1: PTR), but without mentioning all of them she provides information about the methods and approaches applied (Move 2: DTM). Then she concentrates on the third aim (Move 1: PTR) and finally provides a description of the corpus used in her study (Move 2: DTM). Unlike Pho (2008: 238), who has identified cases of move cycles in studies "which have a structure Pilot studyFollow-up study", the above abstract is aimed at advertising research conducted by an experienced scholar.

\section{Conclusions}

Drawing on the results discussed and exemplified above, the following answers can be suggested to the research questions formulated in Section 2 above:

RQ 1: Is there any cross-cultural variation in the writing of conference abstracts?

The analysis of CAs in the groups of writers selected for the study has revealed interesting cross-cultural differences between the ways CAs are composed by native speakers of English, on the one hand and writers from language backgrounds where Slavonic languages are spoken on the other. Apart from variation among the groups of Slavonic writers, namely those from Slovakia, Poland and Ukraine, it has been possible to identify some tendencies in the writing of CAs by Czech writers between 2008 and 2014. The most noticeable 
cross-cultural variation concerns the number of moves and types of moves. While Anglophone writers mostly apply three moves representing three different types, non-Anglophone writers in general prefer two moves only. Two different types of moves are typical of Ukrainian, Slovak and Czech writers from the 2008 group. As regards Czech writers, between 2008 and 2014 there is a clear tendency to apply progressively a higher number of moves and, in particular, a higher number of different types of moves. Therefore, it can be stated that Czech authors have become more confident about the rhetorical organization of abstracts and now attempt to include rhetorical moves traditionally associated with RA abstracts. Concerning the overall rhetorical organization of CAs, the results most similar to those of Anglophone writers, i.e. the application of three different types of moves, have been achieved by Polish writers and Czech writers (with the exception of those from 2008). It must be admitted, however, that there can be other factors influencing the number of different types of moves, such as the stage of research at which the CA is submitted, or the author's intention to present and discuss only the theoretical framework and methodology of the intended research.

The most typical pattern of move sequences - STR PTR DTM - has been applied in 21 CAs. This sequence of rhetorical moves is in full agreement with the rhetorical structure of RA abstracts. However, the moves STF and DTR that usually follow in RA abstracts hardly ever occur, since the CAs analysed mostly comprise only two to four moves ( 73 cases) which usually represent two or three different types of moves (60 cases). The more frequent two-move patterns STR PTR and PTR DTM have been applied by 29 writers.

RQ 2: Is the rhetorical structure of CAs in correspondence with the rhetorical organization and types of moves traditionally ascribed to RA abstracts?

As the results given in all tables in Section 4 prove, the rhetorical organization of CAs is slightly different from that of RA abstracts, especially with regard to the inclusion of Move 4 (Summarizing the findings) and Move 5 (Discussing the research). While Move 1 (Situating the research), Move 2 (Presenting the research) and Move 3 (Describing the methodology) are included in the majority of the CAs analysed, sometimes in the same order as in the rhetorical structure of RA abstracts ( 21 cases), the moves that usually follow in the textual organization of RA abstracts, i.e. Move 4 and Move 5, are included only exceptionally. These differences are caused by the fact that when preparing to submit their CAs scholars usually intend to report on research which is still in progress or is about to commence and, moreover, at the time they compose their CAs, they do not 
usually have their research findings at their disposal, which prevents them from including Move 4 and, consequently, Move 5.

RQ 3: Is the textual organization of CAs written by non-native speakers of English different from that of native speakers?

The textual organization of CAs by non-native speakers of English in general differs from that of native speakers in the fact that abstracts by the latter group tend to be more compact, thus comprising a slightly higher number of moves and in particular a higher number of different types of moves. This variation may be caused by different writing conventions allowing, in the case of some Slavonic writers, digressions and less condensed texts than those usually required of abstracts. Nevertheless, there is a noticeable tendency, for example, in the writing of CAs by Czech scholars, to make abstracts more condensed, thus meeting the usual requirements for scholarly texts in English, such as clarity, economy and precision in communication (cf. Bennett 2016, mentioned in Section 1). However, only further analysis, comprising more data from other non-English speaking discourse communities, can confirm my conclusions.

RQ 4: Does the rhetorical structure of CAs comprise five moves?

As evidenced by the results exemplified in Section 4, hardly any CA comprises five different types of moves. There are only ten CAs of all the 80 analysed here that include more than three types and three of these are written by Anglophone writers, who in general apply a greater variety of possible types of moves. If only the total number of moves is taken into consideration, then it can be stated that about one quarter of CAs (22) comprise four moves and four even include five to six moves. These findings have resulted from the application of move cycles and, in some cases, rather lengthy explanations included in certain types of moves in CAs by non-Anglophone writers. As stated above, the number of moves can also be influenced by the process of CA preparation and culture-specific factors.

As regards recommendations for future conference calls (e.g. for the forthcoming Brno Conference on Linguistics Studies in English, which is to be held in September 2016 in Brno, Czech Republic), it seems highly advisable to require of prospective participants, apart from a certain number of words and a relevant topic, the inclusion of concrete rhetorical types of moves, especially Move 3 (Describing the methodology), which has been included in only 50 to 80 per cent of CAs by non-native speakers of English, and, if possible, also Move 4 
(Summarizing the findings), which has been applied only exceptionally in the data $(0-40 \%$ of CAs). The same recommendations apply to novice writers who intend to submit CAs to receive an invitation to a conference and subsequent publication in conference proceedings.

On the whole, this study has shown that the overall macro-organization of rhetorical moves in CAs is different from that traditionally associated with RA abstracts, although it should be noted that the present investigation concerns only empirical research abstracts from the area of linguistics studies and that the identification of particular types of moves and patterns of move sequences has been based solely on content and function. Only further research into the rhetorical structure of CAs by writers from other language and cultural backgrounds supported by analysis of linguistic realizations of individual types of moves can give a more complete picture of the rhetorical structure of conference abstracts.

\section{References}

Bhatia, V. (1993) Analyzing Genre: Language Use in Professional Settings. London: Longman.

Bennett, K. (2010) 'Academic discourse in Portugal: A whole different ballgame?' Journal of English for Academic Purposes 9, 21-32.

Bennett, K. (2013) 'Discourses of knowledge: Cultural disjunctions and their implications for the language industries.' In: Haase, C. and Schmied, J. (eds) English for Academic Purposes: Practical and Theoretical Approaches. REAL Studies 7. Göttingen: Cuvillier Verlag. 41-54.

Bennett, K. (2015) 'The transparency trope: Deconstructing English academic discourse.' Discourse and Interaction 8 (2), 5-19.

Biber, D., Connor, U. and Upton, T. (2007) Discourse on the Move. Using Corpus Analysis to Describe Discourse Structure. Amsterdam: John Benjamins.

Connor, U. and Upton, T. (eds) (2004) Discourse in the Professions: Perspectives from Corpus Linguistics. Amsterdam and Philadelphia: John Benjamins.

Chamonikolasová, J. (2005) 'Comparing the structures of academic texts written in English and Czech.' In: Huttová, M. et al. (eds) Slovak Studies in English 1. Bratislava: Comenius University. 77-84.

Čmejrková, S. and Daneš, F. (1997) 'Academic writing and cultural identity: The case of Czech academic writing.' In: Duzsak, A. (ed.) Culture and Styles of Academic Discourse. Berlin and New York: Mouton de Gruyter. 40-62.

Dontcheva-Navratilova, O. (2012) 'Cross-cultural differences in the construal of authorial voice in the genre of diploma theses.' In: Berkenkotter, C., Bhatia, V. K. and Gotti, M. (eds) Insights into Academic Genres. Linguistic Insights. Studies in Language and Communication. Vol. 160. Bern: Petr Lang. 301-328.

Flowerdew, L. (2004) 'The argument for using English specialized corpora to understand academic and professional language.' In: Connor, U. and Upton, T. (eds) Discourse in the Professions: Perspectives from Corpus Linguistics. Amsterdam and Philadelphia: John Benjamins. 11-33. 
Hedgcock, J. S. (2005) 'Taking stock of research and pedagogy in L2 writing.' In: Hinkel, E. (ed.) Handbook of Research in Second Language Teaching and Learning. Mahwah and London: Lawrence Erlbaum. 597-613.

Hyland, K. (2000) Disciplinary Discourses: Social Interactions in Academic Writing. Harlow: Longman.

Lillis, T. and Curry, M. J. (2010) Academic Writing in a Global Context: The Politics and Practices of Publishing in English. London and New York: Routledge.

Mauranen, A., Hynninen, N. and Ranta, E. (2010) 'English as an academic lingua franca: The ELFA project.' English for Specific Purposes 29, 183-190.

Mur-Dueňas, P. (2008) 'Analysing engagement markers cross-culturally: The case of English and Spanish business management research articles.' In: Burgess, S. and Martín-Martín, P. (eds) English as an Additional Language in Research Publication and Communication. Linguistic Insights. Studies in Language and Communication. Vol. 61. Bern: Peter Lang. 197-213.

Pho, P. D. (2008) 'Research article abstracts in applied linguistics and educational technology: A study of linguistic realizations of rhetorical structure and authorial stance.' Discourse Studies 10 (2), 231-250.

Pérez-Llantada, C. (2011) 'Constructing the ideal readership: Heteroglossic (dis) engagement in research writing practices across cultures.' In: Bhatia, V. K., Sánchez, P. and Pérez-Paredes, P. (eds) Researching Specialised Languages. Amsterdam: John Benjamins. 25-45

Povolná, R. (2012) 'Cross-cultural differences in the use of discourse markers by Czech and German students of English in the genre of Master's theses.' In: Berkenkotter, C., Bhatia, V. K. and Gotti, M. (eds) Insights into Academic Genres. Linguistic Insights. Studies in Language and Communication. Vol. 160. Bern: Petr Lang. 329-351.

Samraj, B. (2005) 'An exploration of a genre set: Research article abstracts and introductions in two disciplines.' English for Specific Purposes 24, 141-156.

Santos, M. B. (1996) 'The textual organization of research paper abstracts in applied linguistics.' Text, 16 (4), 481-499.

Schmied, J. (2011) 'Academic writing in Europe: A survey of approaches.' In: Schmied, J. (ed.) Academic Writing in Europe: Empirical Perspectives. REAL Studies 5. Göttingen: Cuvillier Verlag. 1-22.

Stašková, S. (2005) 'Options of identity: Authorial presence in research article abstracts.' In: Huttová, A. et al. (eds) Slovak Studies in English 1. Bratislava: Comenius University. 201-207.

Swales, J. M. (1981) Aspects of Article Introduction. Birmingham, UK: The University of Aston. Language Studies Unit.

Swales, J. M. (1990) Genre Analysis. English in Academic and Research Settings. Cambridge: Cambridge University Press.

Swales, J. (2004) Research Genres. Explorations and Applications. Cambridge: Cambridge University Press.

Swales, J. M. and Feak, C. (2009) Abstracts and the Writing of Abstracts. Ann Arbor: The University of Michigan Press.

Tse, P. and Hyland, K. (2010) 'Claiming a territory: Relative clauses in journal decriptions.' Journal of Prgamtics 42, 1880-1889.

Wagner, S. (2011) 'Concessives and contrastives in student writing: L1, L2 and genre differences.' In: Schmied, J. (ed.) Academic Writing in Europe: Empirical Perspectives. REAL Studies 5. Göttingen: Cuvillier Verlag. 23-48. 
Renata Povolná is Associate Professor of English Linguistics at Masaryk University, Brno, Czech Republic. Her research interests lie in the area of discourse analysis, pragmatics and conversation analysis, concentrating mainly on academic discourse. She has published the books Spatial and Temporal Adverbials in English Authentic Face-to-Face Conversation (2003) and Interactive Discourse Markers in Spoken English (2010) and co-authored Cohesion and Coherence in English Discourse (2012). She is co-editor of Coherence and Cohesion in Spoken and Written Discourse (2009) and Discourse Interpretations: Approaches and Applications (2012) published by CSP. She is co-editor of the linguistics journal Discourse and Interaction.

Address: doc. PhDr. Renata Povolná, Ph.D., Department of English Language and Literature, Faculty of Education, Masaryk University, Poř́íćí 9, Brno 603 00, Czech Republic. [e-mail: povolna@ped.muni.cz] 